\title{
Descrição das propostas do Ministério da Educação na avaliação da deficiência intelectual ${ }^{1}$
}

\author{
Aline Aparecida Veltrone ${ }^{2}$ \\ Enicéia Gonçalves Mendes \\ Universidade Federal de São Carlos, São Carlos-SP, Brasil
}

\begin{abstract}
Resumo: Este artigo objetiva descrever e analisar as recomendações oficiais do Ministério da Educação (MEC) para identificação da deficiência intelectual em escolares. O estudo foi realizado por meio da análise de documentos legais e normativos do MEC sobre avaliação da deficiência intelectual. Para tanto, primeiramente foi construído um protocolo de análise que deveria ser preenchido com os seguintes dados: nome do documento, descrição e síntese. O modelo do protocolo de análise foi dividido em três temas: definição da condição da deficiência intelectual, avaliação da condição da deficiência intelectual e atendimento educacional. Os resultados evidenciam que há no país uma indefinição legal a respeito das diretrizes oficiais sobre como identificar os alunos com deficiência intelectual, cujas consequências na prática são ainda desconhecidas.
\end{abstract}

Palavras-chave: educação especial, inclusão escolar, retardo mental, avaliação de necessidades.

\section{Description of the Ministry of Education's proposals concerning the evaluation of intellectual disabilities}

\begin{abstract}
This paper describes and examines the official recommendations of the Brazilian Ministry of Education (MEC) concerning the identification of intellectual disability in students. This study was conducted through the analysis of MEC's legal and normative documents concerning assessment of intellectual disability. First, an analysis protocol was developed to address the following information: document's name, description and synthesis. The model of the analysis protocol was divided into three themes: definition of intellectual disability condition, assessment of intellectual disability condition, and educational support. The results reveal there is legal uncertainty concerning official guidelines on how to identify students with intellectual disabilities, whose consequences are still unknown.
\end{abstract}

Keywords: special education, school inclusion, mental retardation, needs assessment.

\section{Descripción de las propuestas del Ministerio de la Educación en la evaluación en discapacidad intelectual}

\begin{abstract}
Resumen: El objetivo es describir y analizar las recomendaciones oficiales del Ministerio de la Educación (MEC) en la identificación de la discapacidad intelectual en los alumnos. La investigación se realizó mediante el análisis de los documentos legales y normativos del MEC con relación a la evaluación de la discapacidad intelectual. Para eso, primero fue construido un protocolo de análisis que debería ser completado con los siguientes datos: nombre del documento, descripción y síntesis. El modelo del protocolo de análisis fue dividido en tres temas: definición de la condición de la deficiencia intelectual, evaluación de la condición de la deficiencia intelectual y atención educacional. Los resultados exponen que, en el momento, hay en Brasil una indefinición legal respecto a las directrices oficiales acerca de cómo identificar los alumnos con discapacidad intelectual y las consecuencias de esta práctica son aún desconocidas.
\end{abstract}

Palabras clave: educación especial, inclusión escolar, retraso mental, evaluación de necesidades.

A educação especial é uma modalidade de ensino que surgiu especialmente para atender aos alunos marginalizados de participação na escola regular. A prática da avaliação sempre foi considerada necessária, visto que era ela que permitia que se identificasse condições particulares dos alunos

\footnotetext{
1 Este texto foi revisado seguindo o Acordo Ortográfico da Língua Portuguesa (1990), em vigor a partir de $1^{\circ}$ de janeiro de 2009. Este artigo é resultante de pesquisa de doutorado intitulada $A$ inclusão escolar do aluno com deficiência intelectual no estado de São Paulo: Identificação e caracterização, financiada por meio de bolsa de estudo da Fundação de Amparo à Pesquisa do Estado de São Paulo (FAPESP).

${ }^{2}$ Endereço para correspondência:

Aline Aparecida Veltrone. Rua Doutor Qurino, 1730/164. CEP 13.015930. Campinas-SP, Brasil. E-mail: aline_veltrone@hotmail.com
}

que justificassem sua elegibilidade aos serviços educacionais especializados. Na maioria dos casos a avaliação envolvia a exclusão destes alunos das classes comuns e seus encaminhamentos para estruturas separadas, tais como as classes ou escolas especiais Bastos (2002).

No caso específico da deficiência intelectual, a literatura científica brasileira sempre evidenciou a dificuldade nos procedimentos de identificação e diagnóstico desse alunado para a definição de elegibilidade e encaminhamento aos serviços educacionais especializados (Almeida 1984; Denari 1984; Januzzi, 2004; Mendes, 1995). Apesar da ênfase no aspecto intelectual da condição, prevaleceram por muito tempo critérios organicistas, e o foco no indicador de fracasso diante das demandas escolares era atribuído exclusivamente ao alunado, ao seu contexto social e cultural de origem. 
A grande parte do alunado responsabilizado pelo fracasso escolar e pela inadequação escolar foi atribuída à condição de deficiência mental de grau leve, a qual era identificada apenas depois do ingresso do aluno na escola. Para atestar a cientificidade da condição, foram amplamente utilizados os testes de inteligência de Binet que avaliavam a normalidade do aluno comparando o seu quociente intelectual (QI) em relação aos alunos da mesma idade, além da observação da atenção do aluno e sua memória. Portanto, a normalidade do aluno era julgada baseada nos padrões de "aluno ideal" definidos pela escola regular (Januzzi, 2004; Mendes, 1995).

Feito a identificação e as consequentes classificações e categorizações, foram impostas algumas condições para o aluno com deficiência intelectual, tal como o desenvolvimento do ensino especializado segregado. No Brasil, segundo Jannuzzi (2004) esta educação especializada ficou primeiramente conhecida como ensino emendativo e posteriormente foi denominada como educação especial. $\mathrm{O}$ ensino emendativo tinha por objetivo a reabilitação dos alunos com deficiência, isto é, visava a "consertar o que estava errado" para depois tentar inseri-los nos ambientes sociais frequentados pelos demais.

Após a reforma educacional que promoveu a reorganização do sistema educacional brasileiro, baseada nos princípios da inclusão escolar, a matrícula de todos os alunos com deficiência passou a ser preferencial nas classes comuns das escolas regulares. A Constituição da República Federativa do Brasil (1988) e a Lei no 9.394 que instituiu a Lei de Diretrizes e Bases da Educação Nacional (1996) estabeleceram que a educação era direito de todos e trouxeram ao cenário nacional um desestímulo à manutenção, nas escolas públicas, das classes especiais como meio de escolarização dos alunos com deficiência, incluindo aqueles com deficiência intelectual.

A filosofia da inclusão escolar pressupõe que cabe a escola se adaptar aos alunos e não o contrário. Almeja uma escola de qualidade para todos, defende o acesso de todos os jovens e crianças à escola regular, inclusive os provindos dos espaços da educação especial. A escola deve ser o lugar de excelência e escolha. Além disso, a proposta da inclusão escolar ao defender o respeito à diversidade, o reconhecimento político das diferenças tem a obrigação de se reestruturar para que possa atender, satisfatoriamente, todo o alunado (Rodrigues, 2006).

Além disso, Omote, Oliveira, Baleotti e Martins (2005) revelam que para que a inclusão seja bem-sucedida ela envolve o desenvolvimento de atitudes sociais positivas dos agentes (professores, gestores etc.). Entretanto, sem mudanças no contexto maior que fundamenta o sistema educacional no nosso país as atitudes sociais positivas perdem sua força.

Os dados do censo escolar do Instituto Nacional de Estudos e Pesquisas Educacionais (Ministério da Educação, 2006) evidenciam que os alunos com deficiência intelectual compõem o maior contingente dos alunos matriculados nas classes comuns e nos serviços de apoio, representando quase que metade do alunado com necessidades educacionais especiais sendo escolarizados em classes comuns de escolas regulares. Tais dados são corroborados pela literatura sobre deficiência intelectual no qual cerca de 50\% do alunado da educação especial se enquadra nesta condição e que destes, grande maioria dos alunos com deficiência intelectual, seja aproximadamente $80 \%$, se encaixe na condição de grau considerado leve, que é a que justamente apresenta maior desafio para a questão do diagnóstico (Mendes, 1995).

Considerando a perspectiva de garantir a permanência do aluno na classe comum, a identificação e encaminhamento para retirada deste ambiente e encaminhamento para classe ou escola especial perderam sua função. Por outro lado, considerando que a mera inserção dos alunos com deficiência intelectual nas classes comuns não faz desaparecer suas necessidades educacionais especiais, alguma sistemática de avaliação deve ser utilizada a fim de garantir o direito ao atendimento educacional especializado que a legislação prevê a tais alunos.

A identificação deste alunado no Brasil sempre foi e continua sendo uma tarefa difícil de ser realizada. Antes do debate sobre inclusão escolar, havia a exigência de um diagnóstico formal de deficiência feito por profissionais habilitados, em geral da área da psicologia, para que o encaminhamento para os serviços de classe especial ou escola especial fosse considerado (Almeida, 2004; Mendes, 1995). Hoje, se a perspectiva visa a garantir a permanência do aluno na classe comum, o diagnóstico para a identificação e encaminhamento para classe e escola especial perde a sua função, mas ao mesmo tempo aparecem novas propostas de avaliação e práticas que carecem de sistematização e fundamentação, tornando o processo todo arbitrário e podendo comprometer o direito a uma educação devida para as pessoas com deficiência intelectual.

Tendo em vista o número expressivo de alunos identificados na condição de deficiência intelectual nas estatísticas oficiais e as dificuldades atreladas ao processo de como tal aluno pode ser identificado, parece importante questionar como e por quem estes alunos estão sendo avaliados e identificados.

É importante considerar que apesar da porcentagem alta de alunos com deficiência intelectual esta identificação nem sempre é precisa. Isso ocorre porque a nomenclatura e consequente definição do que seja a deficiência intelectual sofreram e ainda sofrem alterações ao longo da história. Esta imprecisão conceitual inclusive trouxe implicações educacionais, sobre os objetivos previstos para o atendimento do alunado com deficiência intelectual, que variam de acordo com a definição de deficiência intelectual que se assume.

Considerando este contexto complexo no qual se encontra o aluno com deficiência intelectual, este estudo teve por objetivo descrever e analisar as diretrizes oficiais do Ministério da Educação (MEC) para a identificação e diagnóstico da deficiência intelectual em escolares. $\mathrm{O}$ estudo se justifica porque a partir desta análise poderemos apontar os elementos necessários para discutir como realizar a identificação, 
diagnóstico, avaliação e atendimento educacional dos alunos com deficiência intelectual.

\section{Método}

A busca dos documentos foi feita no próprio sítio do MEC e foram selecionados tanto documentos legais quanto os documentos normativos, elaborados para definir e organizar o atendimento ao alunado da educação especial na perspectiva da inclusão escolar, dando ênfase para os alunos com deficiência intelectual. O ponto de partida cronológico definido para a seleção dos documentos foi o ano da aprovação da última Lei n ${ }^{\circ}$ 9.394/96 (1996) até o momento atual. Foram encontrados 11 documentos oficiais produzidos de 1996 até o ano de 2009, que foi o documento mais recente encontrado e que faziam referências explícitas ao assunto.

Os documentos foram lidos e analisados, tentando-se responder a seguinte questão: quais são as definições, procedimentos e critérios, bem como instrumentos e profissionais oficialmente recomendados e previstos pelo MEC na identificação dos alunos com deficiência intelectual? Para tanto, primeiramente foi construído um protocolo de análise que deveria ser preenchido com os seguintes dados: nome do documento, descrição e síntese. O modelo do protocolo de análise foi dividido em três temas: definição da condição da deficiência intelectual, avaliação da condição da deficiência intelectual e atendimento educacional. Todos os documentos foram lidos e fichados de acordo com as respectivas categorias.

\section{Resultados}

\section{Identificação dos alunos com deficiência intelectual}

No artigo 5 do Decreto $n^{\circ} 5.296$ (2004) define-se a condição da deficiência intelectual como funcionamento intelectual significativamente inferior à média e associada a duas ou mais áreas de habilidades adaptativas, tais como comunicação, cuidados pessoais, habilidades sociais, utilização da comunidade, saúde e segurança, habilidades acadêmicas, lazer e trabalho. Estas dificuldades devem se manifestar antes da idade dos 18 anos.

Tal definição é idêntica à proposta pela American Association on Mental Retardatation (AAMR), no ano de 1992 (Almeida, 2004) cuja filosofia principal na época era de que a condição adquire uma orientação funcional e que, portanto, o foco da identificação, e consequente classificação, deve ser para prover e definir a intensidade dos apoios necessários para que a pessoa melhore o seu funcionamento em um dado contexto histórico, cultural e social. Embora haja diferença na terminologia adotada nos E.U.A. cujo termo oficial é "retardo mental", e no Brasil, que adota o termo "deficiência intelectual", as condições são equivalentes, e a preferência por um ou outro termo é definida em função do termo que tem menor conotação pejorativa e isto varia de país para país (Mendes, 1995).
Almeida (2004) identifica duas grandes mudanças de concepção e consequente nomenclatura e definição de deficiência intelectual propostas pela AAMR. Pode-se dizer que até meados da década de 1970 prevalecia uma definição de deficiência intelectual em que esta era concebida como algo "incurável" e "permanente", uma condição exclusiva do indivíduo que impedia que ele tivesse participação nos espaços sociais como os demais. Com relação à nomenclatura, utilizava-se "retardo mental" e a partir da década de 1980 ficou conhecido como deficiência mental.

A partir de 2008 a então conhecida AAMR muda seu nome para American Association on Intelectual Disabilities (AAIDD) e propõe a mudança de nomenclatura, de deficiência mental para deficiência intelectual. O termo deficiência mental definido em 2002 já atribuía um caráter multideterminado para a condição. A nomenclatura apenas foi considerada mais adequada e deve ser compreendida enquanto uma incapacidade caracterizada por importantes limitações, tanto no funcionamento intelectual quanto no comportamento adaptativo. Esta nova definição mantém a concepção de que a condição deve ser baseada nos apoios previstos e expande sua definição e conceituação para "criar um sistema multidimensional para diagnosticar, classificar e planejar os apoios para pessoas com retardo mental". Ainda delimita cinco abordagens para se considerar este sistema multidimensional, sendo elas: habilidades intelectuais; comportamento adaptativo (habilidades conceituais, sociais e práticas); participação, interações e papéis sociais; saúde (saúde física, saúde mental, etiologia) e contexto (Luckason e cols., 2006, p. 55).

Pode-se dizer que até 1990 o sistema educacional brasileiro ainda estava pautado sob o princípio da integração, em que prevalecia a concepção de que a deficiência intelectual (conhecida então como retardo mental e deficiência mental) era vista numa perspectiva orgânica e o papel da educação especial era de reabilitação, ofertado principalmente por meio de escolas e classes especiais. Com o surgimento das propostas de inclusão escolar a partir de 1990 começou-se a trabalhar com uma nova perspectiva de deficiência intelectual e consequentemente da educação especial, que deve ter como objetivo oferecer condições para que o aluno tenha acesso aos níveis máximos de desenvolvimento e aprendizagem, e não para que seja "curado". O atendimento deve ser feito por meio das salas de recursos multifuncionais.

$\mathrm{Na}$ atualidade, a condição da deficiência intelectual deve ser compreendida enquanto a interação entre uma pessoa com funcionamento intelectual limitado e seu ambiente. Por estar guiada por uma orientação funcional da condição da deficiência, existe um forte compromisso da necessidade de classificação baseada na intensidade dos apoios necessários. A premissa básica é a de que com os apoios individualizados certos a pessoa geralmente vai melhorar a maneira como funciona na vida cotidiana.

Comparando-se as definições, observa-se que os documentos oficiais publicados pelo MEC mantêm a premissa definida pela AAIDD de que a condição da deficiência é 
funcional, e que não pode estar circunscrita somente à condição orgânica ou individual da pessoa. É importante ressaltar que nos documentos consultados o termo deficiência intelectual aparece como deficiência mental; termo este preservado nas citações literais feitas ao longo do texto.

No caso específico dos documentos voltados para a definição da deficiência intelectual, as variáveis a serem consideradas dizem respeito ao contexto educacional no qual o aluno se encontra: "a ênfase desloca-se, pois, do aluno com defeito para situar-se na resposta educativa da escola, sem que isso represente negação da problemática vivida pelo educando" (Ministério da Educação, 2006a, p. 28). Também prevalece a preocupação em se definir a deficiência intelectual num contexto multideterminado, no qual diversas variáveis devem ser consideradas, em especial as que dizem respeito à interação indivíduo e o meio:

Com esse enfoque, faz-se necessário avaliar os apoios que são oferecidos para as pessoas evoluírem nas suas habilidades adaptativas. Trata-se de uma proposta importante, na medida em que desloca o eixo da avaliação da pessoa, propriamente dita, para a existência e qualidade dos apoios de que ela necessita (Ministério da Educação, 2006b, p. 38).

Esta nova abordagem da definição da condição da deficiência intelectual é importante uma vez que vem contrapor práticas já denunciadas pela literatura de que na grande maioria das vezes a condição da deficiência é algo que se atribui exclusivamente ao sujeito e não se considera o ambiente e outras variáveis (Balduíno, 2006; Lopes, 2005; Patto, 1996; Veltrone, 2008).

Outra problemática evidenciada é de que na prática, em especial nas instituições escolares, existe uma confusão na definição, em que o fracasso escolar acaba sendo confundido com deficiência intelectual e vice-versa:

Não existem critérios objetivos e confiáveis para relacionar a deficiência - enquanto atributo isolado do indivíduo e as dificuldades de aprendizagem que enfrenta, pois a maioria destas é devida às condições educacionais incapazes de suprir-lhes as necessidades que, nem sempre, decorrem de deficiência, com base orgânica (Ministério da Educação, 2006a, p. 33).

O documento deixa claro que a relação fracasso escolar e deficiência intelectual não é de causa e efeito e a definição da deficiência intelectual não pode ser reduzida a esta lógica. Esta relação muitas vezes é fruto de uma estrutura educacional que foi e é organizada para atender determinado tipo de aluno, com características homogêneas de ritmos de aprendizagem e desenvolvimento. A deficiência intelectual acaba sendo confundida com fracasso escolar porque estes alunos tem um ritmo próprio de desenvolvimento e aprendizagem que parece não ser considerado pelas instituições escolares:
O aluno com deficiência mental tem dificuldade de construir conhecimento como os demais e de demonstrar a sua capacidade cognitiva, principalmente nas escolas que mantêm um modelo conservador de atuação e uma gestão autoritária e centralizada. Essas escolas apenas acentuam a deficiência e, em consequência, aumentam a inibição, reforçam os sintomas existentes e agravam as dificuldades do aluno com deficiência mental (Ministério da Educação, 2006a, p. 12).

Apesar de se considerar que a condição da deficiência intelectual não necessariamente tem relação direta com fracasso escolar e que muitas vezes as duas condições são confundidas porque o aluno tem um ritmo próprio de construção do conhecimento, a definição da condição de deficiência intelectual sempre vai estar relacionada com uma necessidade educacional especial. Ao se considerar a definição da deficiência e das consequentes necessidades educacionais especiais é também preciso situá-las em um contexto mais amplo que diz respeito: "ao aprendiz, quanto ao contexto em que a aprendizagem ocorre e a identificação dessas necessidades deve impulsionar a comunidade escolar às providências cabíveis para satisfazê-las" (Ministério da Educação, 2006b, p. 23). A identificação deve levar em conta as diversas variáveis e também deve ser utilizada para basear uma decisão a ser tomada sobre o aluno, uma decisão que favoreça seu processo educacional.

É preciso também considerar tanto as características funcionais do alunado, que dizem respeito "às habilidades básicas que permitem que o aluno enfrente as demandas das diferentes etapas do fluxo da educação básica" (Ministério da Educação, 2006b, p. 62) quanto às características do ambiente no qual o sujeito se encontra.

A concepção das características funcionais considera que é preciso que o aluno apresente características próprias e individuais que o façam progredir nos estudos e ter sucesso na aprendizagem e desenvolvimento. Apesar das características para o sucesso na relação ensino e aprendizagem serem desejáveis para o aluno, a responsabilidade para o surgimento, manutenção e motivação destas é também da instituição escolar, a qual envolve as competências curriculares e a utilização dos conteúdos das diferentes áreas de conhecimento do ensino fundamental, tais como: língua portuguesa, matemática, geografia, temas transversais (Ministério da Educação, 2006b, p. 6).

Pela análise dos documentos legais e oficiais do MEC percebe-se que em alguns documentos a condição da deficiência intelectual é definida e reconhecida como uma categoria distinta e se caracteriza por déficits nas dimensões intelectuais e adaptativas.

Em outros documentos, a visão oficial, quando se refere especificamente à questão da educação escolar, chama a atenção para a responsabilidade histórica da escola na produção da deficiência intelectual. Entretanto, em outros 
momentos ressalta que dificuldades escolares não implicam necessariamente em deficiência intelectual.

Há sempre a recomendação para que a condição do aluno seja compreendida enquanto um processo em que é preciso conhecer as condições de desenvolvimento, de aprendizagem, as potencialidades do aluno para a delimitação da condição da deficiência intelectual. Além disso, a definição só importa se resultar em apoios para a pessoa. Nas recomendações há referências explícitas considerando que os apoios devem ser extensivos para os alunos com dificuldades de aprendizagem em geral, associadas ou não às deficiências:

A presença da deficiência não implica, sempre, em dificuldade de aprendizagem. De outro lado, inúmeros alunos apresentam distúrbios de aprendizagem sem serem, necessariamente, portadores de deficiência. Mas, ambos os grupos têm necessidades educacionais especiais, exigindo respostas educativas adequadas, além de medidas preventivas para evitar que, na escola, os casos se originem ou intensifiquem (Ministério da Educação, 2006b, p. 32).

Concluindo, pode-se dizer que o conjunto dos documentos não oferece uma definição consistente do que é a deficiência intelectual. A própria definição da AAMR, por exemplo, que é utilizada em alguns documentos, não é atualizada pela definição mais recente publicada por esta associação. Embora a condição seja reconhecida como uma categoria distinta nas estatísticas oficiais, na definição do alunado e nas recomendações quanto ao atendimento educacional específico, a categoria parece se confundir com dificuldades escolares de modo mais geral. Também parece existir certo descrédito na necessidade de identificar este tipo de alunado, em detrimento da adoção do conceito de necessidades educacionais especiais.

\section{Avaliação dos alunos com deficiência intelectual}

Na legislação nacional, não encontramos uma definição específica para a avaliação da deficiência intelectual, mas sim para a condição de deficiência de uma maneira geral, na qual esta deve ser diagnosticada e caracterizada por equipes de saúde para concessão de benefícios (Decreto $\left.n^{0} 3.298,1999\right)$. No caso específico da deficiência intelectual, várias áreas de conhecimento (psicologia, sociologia, antropologia) têm teorias importantes quando se discute a identificação da deficiência intelectual (Ministério da Educação, 2007a, p. 14).

No contexto escolar, a avaliação preconizada deve estar voltada para a identificação das necessidades educacionais especiais e avaliação das condições de ensino e aprendizagem: "avaliação pedagógica do processo de ensino e aprendizagem, inclusive para a identificação das necessidades educacionais especiais e a eventual indicação dos apoios pedagógicos adequados" (Ministério da Educação, 2001, p. 48).
A avaliação voltada para a identificação das condições de ensino e aprendizagem tem uma orientação pedagógica, e não diagnóstica: "no decorrer do processo educativo, deverá ser realizada uma avaliação pedagógica dos alunos que apresentem necessidades educacionais especiais, objetivando identificar barreiras que estejam impedindo o processo educativo em suas múltiplas dimensões" (Ministério da Educação, 2001, p. 34). A avaliação deve considerar o desenvolvimento das relações de ensino e aprendizagem e todas as variáveis que estão presentes. Para tanto, é preciso considerar o próprio aluno: nível de desenvolvimento e condições pessoais; o contexto educacional (instituição educacional escolar e ação pedagógica); e família (características do ambiente familiar e do convívio familiar) (Ministério da Educação, 2006b).

Ao ter como objetivo a identificação de barreiras à aprendizagem, a avaliação também tem como objetivo a identificação dos apoios necessários para o consequente sucesso na escolarização de todos os alunos, inclusive os alunos com deficiência e, portanto, deve estar voltada para o progresso dos alunos. A indicação dos serviços deve ser feita para o planejamento dos apoios necessários, visando seu desenvolvimento e aprendizagem:

No caso das necessidades educacionais especiais, os rumos da avaliação devem estar a serviço da implementação dos apoios necessários ao progresso e ao sucesso de todos os alunos, bem como para a melhoria das respostas educativas oferecidas no contexto educacional, escolar e, se possível, familiar (Ministério da Educação, 2006b, p. 8).

Da análise dos documentos, identifica-se que as práticas avaliativas devem ser organizadas de modo a fornecer subsídios para a indicação dos apoios e recursos pedagógicos que contribuam para a remoção das barreiras de aprendizagem de todos os alunos, inclusive dos alunos com deficiência intelectual.

Com relação às teorias, instrumentos e profissionais que devem atuar nesta avaliação, considera-se fortemente a necessidade de uma avaliação que esteja calcada em objetivos pedagógicos, em detrimento de toda uma gama de conhecimento que costumava ser utilizada na avaliação para identificação da deficiência intelectual. Nesse sentido, as práticas classificatórias, tais como os testes psicológicos devem ser restritos a situações específicas, e na avaliação devem-se considerar também as diversas variáveis que incidem na aprendizagem humana, que recebe influência do contexto social imediato (Ministério da Educação, 2006b, p. 43).

Os profissionais previstos para realizar a avaliação devem ser aqueles que diretamente atuam com o aluno: "deverá ser formada no âmbito da própria escola, uma equipe de avaliação que conte com a participação de todos os profissionais que acompanhem o aluno" (Ministério da Educação, 2001, p. 34). A defesa pelos profissionais da escola é justamente 
em decorrência de estes terem os conhecimentos necessários para uma atuação nas situações de ensino e aprendizagem e provavelmente para a avaliação pedagógica.

Em outros trechos os documentos legais e oficiais reconhecem a importância da avaliação pedagógica ser realizada pelos próprios profissionais da escola, mas, por outro lado, também identificam que este é um processo novo e que nesta fase de transição é preciso considerar a ajuda dos profissionais do campo da educação especial na avaliação. $\mathrm{Na}$ medida em que a equipe da escola puder realizar sozinha a identificação das necessidades educacionais dos seus alunos, a educação especial deve contribuir como assessoramente especializado (Ministério da Educação, 2006b). Portanto, na avaliação para a identificação das necessidades educacionais especiais e provimento dos apoios ainda é recomendada a equipe multiprofissional, composta de profissionais de diversos campos de conhecimento (Ministério da Educação, 2001, p. 34-35).

Em relação aos instrumentos é recomendado o descarte dos testes padronizados e a construção de instrumentos não padronizados pelo próprio ambiente escolar, de acordo com os respectivos contextos de ensino e aprendizagem, o qual envolve necessariamente a participação do professor, a observação, construção de diário de classes, relatórios, fichas que coletem dados sobre o aluno e contexto escolar em questão (Ministério da Educação, 2006b, p. 40).

Além das observações, outras avaliações pontuais da condição do aluno são indicadas para serem feitas, tais como: análise da produção escolar dos alunos, análise de documentos que orientam a organização escolar, entrevistas etc. (Ministério da Educação, 2006b, p. 40).

Sumarizando, esta nova avaliação tem como enfoque várias medidas que possam dar conta de analisar todos os múltiplos fatores que interferem na aprendizagem. Nesta avaliação o professor assume papel importante, e deve ser preparado para avaliar as necessidades dos alunos e utilizar o diálogo e a observação. Também devem ser envolvidos o próprio aluno e sua família, bem como outros profissionais (Ministério da Educação, 2006b).

Com base no que foi descrito, percebe-se que a avaliação dos alunos está de acordo com a condição de que ela deve prover apoio e remover possíveis barreiras no processo de ensino e aprendizagem.

Na perspectiva da avaliação pedagógica não existe mais a exigência e necessidade do diagnóstico da deficiência intelectual feito por profissionais da área da psicologia para identificação e encaminhamento para classe ou escola especial. A avaliação pedagógica deve ser utilizada para melhorar as condições de ensino e aprendizagem desenvolvidas na escola regular (Almeida, 2004; Mendes, 1995).

Contudo, conforme a própria definição oficial do MEC adotada em alguns documentos, ainda se considera a necessidade de identificação da deficiência intelectual envolvendo procedimentos formais de avaliação intelectual e do comportamento adaptativo, tais como os testes que possam medir a inteligência, bem como o desenvolvimento e o comportamento adaptativo.

Há diversas recomendações para avaliações que levem em consideração todas as variáveis envolvidas na condição da deficiência intelectual, considerando para isso o ambiente escolar e cultural no qual o aluno se encontra e que sirva para definir os apoios. A avaliação para a identificação é negligenciada e em muitos momentos desprezada, ao passo que a avaliação para fins de ensino é priorizada.

Caberia indagar se tal situação não estaria conduzindo a práticas de identificação arbitrárias e subjetivas, e se não estariam dificultando a prescrição dos apoios necessários a esta parcela da população.

\section{Ensino, aprendizagem e atendimento educacional}

A educação tem por finalidade possibilitar que os educandos tenham acesso a níveis mais elevados de desenvolvimento e aprendizagem. Em termos legais, a Constituição da República Federativa do Brasil (1988) e a Lei no 9.394/96 que trata sobre a Lei de Diretrizes e Bases da Educação Nacional defendem que a finalidade maior da educação é o pleno desenvolvimento da pessoa, seu preparo para o exercício da cidadania e sua qualificação para o trabalho.

Os alunos com deficiência intelectual também devem ter acesso a um sistema educacional que tenha o compromisso político com sua educação, oferecendo níveis elevados de desenvolvimento e aprendizagem. A educação especial adquire extrema importância na definição, provimento e organização de serviços educacionais especializados para o atendimento das necessidades educacionais dos alunos com deficiência intelectual, e para isso, devem-se prover professores especializados, currículos, técnicas e recursos educativos específicos para atender a este alunado (Ministério da Educação, 2001, 2006a, 2007b).

O atendimento educacional especializado é um item previsto quando se fala na avaliação da condição da deficiência intelectual. Os objetivos previstos para este atendimento são: "identificar, elaborar e organizar recursos pedagógicos de acessibilidade que eliminem as barreiras para a plena participação dos alunos, considerando suas necessidades específicas". (Ministério da Educação, 2007b, p. 10).

Em relação à deficiência intelectual, a partir do momento em que um dos elementos que a define é a ausência de compreensão por parte da escola da maneira com que o aluno lida com o saber, com a produção de conhecimento, $\mathrm{o}$ atendimento educacional especializado deve privilegiar o desenvolvimento e a superação de seus limites intelectuais (Ministério da Educação, 2007a). O referido documento ainda coloca:

$\mathrm{O}$ atendimento educacional especializado para as pessoas com deficiência mental está centrado na dimensão subjetiva do processo de conhecimento. $\mathrm{O}$ conhecimento acadêmico refere-se à aprendizagem 
do conteúdo curricular; o atendimento educacional especializado, por sua vez, refere-se à forma pela qual o aluno trata todo e qualquer conteúdo que lhe é apresentado e como consegue significá-lo, ou seja, compreendê-lo (Ministério da Educação, 2007a, p. 23).

O documento ainda afirma a necessidade de propiciar aos alunos com deficiência intelectual condições e liberdade para que possam construir sua inteligência, dentro do quadro de recursos intelectuais que lhes são disponíveis, tornandose agentes capazes de produzir significado/conhecimento. Em termos organizacionais, há referências explícitas de que o atendimento especializado não pode ser confundido com "serviço de reforço", pois seus objetivos são específicos para as condições de desenvolvimento do alunado, segundo suas necessidades e capacidades (Ministério da Educação, 2007b).

Por outro lado, há referências também de que o atendimento educacional especializado deve ser diferenciado daqueles da sala de aula comum: "as atividades desenvolvidas no atendimento educacional especializado diferenciam-se daquelas realizadas na sala de aula comum, não sendo substitutiva à escolarização. Esse atendimento complementa e/ ou suplementa a formação com vistas à autonomia e independência na escola e fora dela" (Ministério da Educação, 2007b, p. 10).

Ainda com relação à sua organização, está previsto que $\mathrm{o}$ atendimento educacional especializado seja oferecido por meio das salas de recurso multifucional na própria escola ou em outra escola de ensino regular:

Realizado, prioritariamente, na sala de recursos multifuncionais da própria escola ou em outra escola de ensino regular, no turno inverso da escolarização, não sendo substitutivo às classes comuns, podendo ser realizado, também, em centro de atendimento educacional especializado da rede pública ou de instituição privada, sem fins lucrativos, conveniada com a Secretaria de Educação ou órgão equivalente (Ministério da Educação, 2009, p. 5).

A avaliação do atendimento educacional especializado deve servir para que se possa alterar práticas pedagógicas e aperfeiçoar condições de ensino e aprendizagem que favoreçam o desenvolvimento do aluno. A orientação da avaliação a ser realizada na classe comum também deve ser voltada para identificar a aprendizagem dos alunos, centrando-se no que ele sabe em detrimento do que não sabe (Ministério da Educação, 2007a). Especificamente no caso do aluno com deficiência intelectual é preciso romper com estereótipos e preconceitos de que estes alunos sabem pouco e consequentemente devem receber um conteúdo mais fraco. É preciso oferecer condições de ensino para que o aluno possa lidar com o pensamento, raciocínio e estabelecer relação simbólica com o meio (Ministério da Educação, 2007a).
O conjunto dos documentos oficiais parece indicar que para alunos com deficiência intelectual o atendimento educacional especializado se define pela negativa: não pode ser reforço pedagógico, não pode envolver atividades da classe comum, não pode ser concreto e empobrecido.

Os documentos parecem ignorar que a condição de deficiência intelectual não é um conceito monolítico, pois engloba desde pessoas com dificuldades circunscritas à aprendizagem acadêmica, até indivíduos com dificuldades acentuadas em todos os domínios da existência humana, e que, portanto, é impossível estipular quaisquer generalizações para a categoria como se fosse um único bloco de indivíduos com as mesmas necessidades educacionais especiais.

Por outro lado, percebe-se que os documentos não fornecem diretrizes mínimas sobre como deve ser o atendimento educacional especializado para alunos com deficiência intelectual, e ainda permitem questionar, onde e como os alunos vão construir habilidades acadêmicas mínimas tais como aprender ler, escrever e contar? Conforme os documentos, atividades desta natureza não podem ser trabalhadas no atendimento educacional especializado, então se espera que um professor de ensino regular tenha a responsabilidade de ensinar o conteúdo do currículo? Pelo menos é esta a interpretação inusitada a que se chega diante da análise dos documentos, que, entretanto, não esclarecem explicitamente qual a função do serviço de atendimento especializado no caso dos alunos com deficiência intelectual.

\section{Considerações finais}

Da descrição das propostas oficiais do MEC percebe-se que há um descompasso, pois alguns documentos apresentam uma definição baseada na proposta da AAIDD, a qual pressupõe um processo de identificação da deficiência intelectual que envolve procedimentos formais de avaliação intelectual e do comportamento adaptativo. Por outro lado, vários outros documentos negligenciam a necessidade de identificação, e favorecem a avaliação para o ensino pelos profissionais da escola, utilizando critérios subjetivos e, talvez arbitrários, para definir quais os alunos com deficiência intelectual irão se beneficiar dos serviços especializados, além da matrícula na classe comum.

Se por um lado as definições avançam ao considerar a deficiência intelectual enquanto algo que deve ser multidimensionado e não apenas centrado no aluno, por outro lado, não oferecem diretrizes claras sobre procedimentos de identificação, que ainda estão vagos e podem promover a elegibilidade aleatória dos alunos com essa condição.

É importante considerar a identificação como algo que necessita ao menos de critérios comuns para avaliação, visto que é ela que irá definir para quem e como serão os apoios à escolarização oferecidos a estes alunos. Consideramos que a discriminação positiva é necessária para equiparar as oportunidades dentro da política da inclusão escolar, sendo importante identificar como e quem é o alunado que está recebendo este tratamento diferenciado. 
Entretanto, temos que considerar que esta inconsistência presente na legislação educacional brasileira sofre reflexos da inconsistência que cerca o campo da educação especial no que diz respeito à definição e consequente nomenclatura da deficiência intelectual.

É sabido que no campo da educação especial busca-se constantemente a melhor definição e nomenclatura para o termo deficiência intelectual, a fim de evitar rótulos, estigmas e preconceitos. A literatura científica tem ainda evidenciado que este não é um construto monolítico, mas que vem sendo interpretado e reinterpretado ao longo dos tempos de acordo com a avaliação de "juízes externos" (sociedade, escola, família etc.). Talvez esta seja uma razão da dificuldade em se definir a deficiência intelectual, bem como o melhor tipo de atendimento educacional para estes alunos.

No cenário educacional brasileiro percebemos esta dificuldade e inconsistência na delimitação da nomenclatura, definição e atendimento educacional dos alunos com deficiência intelectual. Ressaltamos ainda que simplesmente adotar definições de outros países, com outras realidades educacionais pode ser dificultoso. Por exemplo, a nova definição da AAIDD propõe avaliar o funcionamento intelectual e também adaptativo, como realizar esta avaliação adaptativa no Brasil se quase não temos testes validados para nossa realidade? E se for somente por critérios de observação, como garantir que exista um padrão de avaliação para que ela não seja arbitrária e subjetiva?

A adoção de nomenclaturas propostas deve vir acompanhada de mudanças conceituais, estruturais, políticas e sociais. E, no caso brasileiro, um caminho para evitar os descompassos propostos entre tendências internacionais, legislação e prática dos profissionais seria o desenvolvimento de uma melhor articulação entre as decisões do poder público e participação das comunidades escolares nestas decisões. As mudanças não podem simplesmente ser impostas de cima para baixo, sem considerar a realidade das escolas e professores que diretamente vão lidar com elas. No caso específico da definição da deficiência intelectual este fato é ainda mais agravante, levando em consideração que o olhar que temos sobre ela é influenciado pelo contexto social, econômico, político, cultural do qual fazemos parte.

Anunciar políticas de inclusão escolar voltadas para todos os alunos com "necessidades educacionais especiais", genericamente falando, pode ser uma medida bem intencionada, mas isso implica em ampliar o financiamento dos serviços de apoio para abranger um grande contingente de alunos que até então nunca foi considerado como alunado da educação especial. Por outro lado, sem ampliação de financiamento corre-se o risco de que alunos com dificuldades escolares menores possam se beneficiar dos serviços de apoio, supostamente destinados a alunos com deficiências, de que as estatísticas estejam sendo inflacionadas com estes novos alunos da "educação especial", enquanto os alunos com deficiências continuam fora das escolas.
Pode-se dizer que não há diretrizes claras em nenhum dos três aspectos investigados nos documentos que passam a mensagem de que a identificação de alunos com deficiência intelectual é desnecessária, que a indicação de suportes é subjetiva e arbitrária, e que o atendimento especializado deve ser qualquer coisa menos alguma atividade voltada para a escolarização. Tal contexto pode favorecer o apagamento da diferença decorrente da deficiência intelectual e, consequentemente, a falta de provisão de suportes para estes alunos.

Para alguns tal situação é desejável, pois os alunos pelo menos não estão sendo oficialmente rotulados. Entretanto, as estatísticas indicam que $50 \%$ dos alunos considerados com "necessidades educacionais especiais" foram identificados e computados como estudantes com deficiência intelectual. Quem são afinal estes alunos, como e por quem foram identificados, e como vêm se dando seus processos de escolarização nas escolas comuns? E quais as consequências para a vida desses alunos diante do fato de estarem sendo escolarizados e socializados como pessoas com deficiência intelectual, sem terem conhecimento de que independente de avaliações psicológicas eles continuam sendo arbitrariamente rotulados?

Este estudo trouxe uma contribuição importante, pois sistematizou e aprofundou a análise das informações presentes nos documentos legais e oficiais sobre a avaliação do aluno com deficiência intelectual no contexto educacional brasileiro, evidenciando a necessidade de procedimentos mais sistemáticos que incluam critérios para identificação, diagnóstico e atendimento educacional.

Por se tratar de um estudo teórico há a limitação de não sabermos até que ponto esta inconsistência legal se reflete na prática das escolas e, portanto, destacamos a importância da realização de estudos que possam analisar a relação estabelecida entre a legislação e as diferentes realidades educacionais para verificar as consequências pragmáticas desta indefinição legal na avaliação dos alunos com deficiência intelectual.

\section{Referências}

Almeida, C. S. (1984). Análise dos motivos de encaminhamento de alunos de classes comuns a classes especiais nas escolas públicas de primeiro grau. Dissertação de mestrado não publicada, Universidade Federal de São Carlos, São Carlos, SP.

Almeida, M. A. (2004). Apresentação e análise das definições de deficiência mental propostas pela AAMR - Associação Americana de Retardo Mental de 1908 a 2002. Revista de Educação PUC-Campinas, (16), 33-48.

Balduíno, M. M. M. (2006). Inclusão escolar de alunos portadores de deficiência mental: Com a palavra os professores. Dissertação de mestrado não publicada, Universidade de Brasília, Brasília. 
Bastos, M. G. A. (2002). Diagnóstico das necessidades educacionais especiais: Evolução e novas tendências. In R. P. Magalhães (Org.), Reflexões sobre a diferença (pp. 86-99). Fortaleza: Edições Demócrito Rocha.

Constituição da República Federativa do Brasil. (1988, 5 de outubro). Recuperado em 10 junho 2009, de http://www. senado.gov.br/sf/legislacao/const

Decreto No. 3.298. (1999, 20 de dezembro). Regulamenta a Lei n. 7.853 de 24 de outubro de 1989, dispõe sobre a Política Nacional para a Integração da Pessoa Portadora de Deficiência, consolida as normas de proteção e dá outras providências. Corde-Brasília: Presidência da República.

Decreto No. 5.296. (2004, 2 de dezembro). Regulamenta as Leis n. 10.048, de 8 de novembro de 2000, que dá prioridade de atendimento às pessoas que especifica, e 10.098, de 19 de dezembro de 2000, que estabelece normas gerais e critérios básicos para a promoção da acessibilidade das pessoas portadoras de deficiência ou com mobilidade reduzida, e dá outras providências. Brasília: Presidência da República.

Denari, F. E. (1984). Análise dos critérios e procedimentos para a composição de clientela de classes especiais para deficiente mentais educáveis. Dissertação de mestrado não publicada, Universidade Federal de São Carlos, São Carlos, SP.

Ministério da Educação. Instituto Nacional de Estudos e Pesquisas Educacionais Anísio Teixeira. (2006). Censo escolar 2006. Brasília: INEP.

Januzzi, G. S. M. (2004). A educação do deficiente no Brasil: Dos primórdios ao início do século XXI (2a ed.). Campinas: Autores Associados.

Lei No. 9.394, de 20 de dezembro de 1996. (1996, 20 de dezembro). Lei de Diretrizes e Bases da Educação Nacional. Diário Oficial da União, Seção 1.

Lopes, N. A. (2005). Deficiência e inclusão escolar: Um estudo sobre representações sociais. Dissertação de mestrado não publicada, Universidade de Brasília, Brasília.

Luckason, R., Borthwick-Duffy, S., Buntinx, W. H., Coulter, D. L., Craig, E. M., Reeve, A., et al. (2006). Mental retardation: Definition, classification, and systems of supports. Washington, DC: American Association on Mental Retardation.

Mendes, E. G. (1995). Deficiência mental: A construção cientifica de um conceito e a realidade educacional. Tese de Doutorado não publicada, Universidade de São Paulo, São Paulo.

Ministério da Educação. Secretaria de Educação Especial. (2001). Diretrizes nacionais para a educação especial na educação básica. Brasília: SEESP.

Ministério da Educação. Secretaria de Educação Especial. (2006a). Educação inclusiva: Atendimento educacional especializado para a deficiência mental. Brasília: SEESP.
Ministério da Educação. Secretaria de Educação Especial (2006b). Saberes e práticas da inclusão: Avaliação para identificação das necessidades educacionais especiais. Brasília: SEESP.

Ministério da Educação. Secretaria de Educação Especial. (2007a). Atendimento educacional especializado: Formação continuada a distância de professores para atendimento educacional especializado para deficiência mental. Brasília: SEESP.

Ministério da Educação. Secretaria de Educação Especial. (2007b). Politica nacional de educação especial na perspectiva da educação inclusiva. Brasília: SEESP.

Ministério da Educação. Secretaria de Educação Especial. (2009). Diretrizes operacionais para a educação especial. Brasília: SEESP.

Omote, S., Oliveira, A. A., Baleotti, L., \& Martins, S. E. S. O. (2005). Mudança de atitudes sociais frente à inclusão. Paidéia (Ribeirão Preto), 15(32), 387-396.

Patto, M. H. S. (1996). A produção do fracasso escolar: Histórias de submissão e rebeldia. (2a ed.). São Paulo: TA Queiroz.

Rodrigues, D. (2006). Dez idéias (mal) feitas sobre a educação inclusiva. In D. Rodrigues (Org.), Inclusão $e$ educação: Doze olhares sobre a educação inclusiva (pp. 299-318). São Paulo: Summus.

Veltrone, A. A. (2008). A inclusão escolar sob o olhar dos alunos com deficiência mental. Dissertação de mestrado não publicada, Universidade Federal de São Carlos, São Carlos, SP.

Aline Aparecida Veltrone é Doutora em Educação Especial pelo Programa de Pós-graduação em Educação Especial da Universidade Federal de São Carlos.

Enicéia Gonçalves Mendes é Professora Adjunta do Departamento de Psicologia e Programa de Pós-graduação em Educação Especial da Universidade Federal de São Carlos.

Recebido: 07/01/2010

$1^{a}$ revisão: 26/03/2010

$2^{a}$ revisão: $26 / 04 / 2010$

Aceite final: $20 / 12 / 2010$ 